\title{
Study on the Realization of the Value of Agricultural Cultural Heritage in the Strategy of Revitalizing Villages
}

\author{
Feng Qu, Ling Bai, Guimei Cao \\ School of Management, Fujian Agriculture and Forestry University, Fuzhou, Fujian, China
}

Keywords: country rejuvenation strategy; agricultural cultural heritage; value realization.

\begin{abstract}
Under the background of the strategy of rural revitalization, through the activation of agricultural cultural heritage, the coordinated development of the protection and development of agricultural cultural heritage is realized, the value of agricultural culture is promoted, and a new industry form is formed, making it one of the sources of rural revitalization.
\end{abstract}

\section{Introduction}

The report of the 19th CPC National Congress pointed out that the implementation of the strategy for rural revitalization. A deep understanding of the objective requirements for the development of agricultural cultural heritage, exploration of the path of the activation of agricultural cultural heritage, the realization of the coordinated development of agricultural cultural heritage protection and development, enhance the value of agricultural culture, making it one of the sources of rural rejuvenation.

\section{Fujian's Agricultural Cultural Heritage}

At present, there are 25 selected important agricultural cultural heritages in China. By activating agricultural cultural heritage, raising the income of local residents and improving the living environment, it is not only a manifestation of precision poverty alleviation, but also the protection of unique agricultural resources, forestry resources, water resources, and marine fishery resources.

\subsection{Rich types of agricultural cultural heritage}

As the location of the country's first cultural and ecological experiment protection area, Fujian has a long and complete agricultural culture system. Agricultural cultural resources include rice cultivation culture, mountain planting, hill planting, and special product species; forestry cultural resources include bamboo, flowers, forest parks, tourist attractions, ancient trees, forestry species, and other resource types; marine fishery cultural resources include Fisheries processing, aquaculture, fishing, fishery, food and other types.

\subsection{Outstanding features of agricultural cultural heritage}

Fujian's agricultural cultural heritage is characterized by its completeness, richness, system, and high cultural value, and it occupies an important position in China's agricultural cultural heritage. Jointly terraced fields of Youxi and Jasmine tea production in Fuzhou have become important cultural heritages in the world. The representative agricultural cultural heritage of tea in our province is clear, the system is complete, the cultural value is high, and the potential economic value is significant.

2.3 The base for the development of the tourism development of agricultural cultural heritage is superior

Fujian's economy has developed at a faster rate, and governments at all levels have invested more heavily in the development of agricultural and cultural related industries. According to the statistics of the Provincial Tourism Bureau, in 2016, the number of tourists received by Fujian reached 315 
million, an increase of 18.1\% year-on-year, 4.1 percentage points higher than the same period of last year, and total tourism revenue was nearly 400 billion yuan, a year-on-year increase of $25.3 \%$, which is higher than the national total. The growth in the number of people and total income was 6.4 and 11.7 percentage points. With the expansion of the influence of the brand new Fujian, it is expected that the number of tourists in our province will further increase.

\subsection{Large potential for tourism development in agricultural cultural heritage}

The development of agricultural cultural heritage is of great value for enhancing the cultural soft power of our province and increasing cultural attraction. With the continuous increase of the economic strength of our province, the protection of agricultural cultural heritage will continue to increase, and the value of agricultural cultural heritage will increase in value along with economic development, thus further enhancing the potential of agricultural cultural tourism development in our province.

\section{Problems in realizing the value of Fujian agricultural cultural heritage}

Now, there are real problems in the realization of understanding, interest coordination, etc., which reflect the deep problems in the academic community and the society's recognition of the value of agricultural cultural heritage and the use of methods.

The Administrative Measures on Important Agricultural Cultural Heritage pointed out that the agricultural cultural heritage should be passed down from history to the present and still have strong production functions, providing guarantees for local agricultural production, residents' income, and social welfare, which will be conducive to the promotion of regional sustainable development. The cultural heritage of agriculture is not only protected and inherited, but also needs to be conducive to the sustainable development of the regional economy and improve the residents' income and social welfare.

As a special living cultural heritage, agricultural cultural heritage is properly used in protection and inheritance, and giving full play to its economic value is its inherent attribute. The lack of understanding of the economic attributes of agricultural cultural heritage has led to the lack of incentive for some government agencies to protect agricultural cultural heritage. At present, the agricultural cultural heritage is almost in the first industry stage, which restricts the promotion of cultural influence and is not conducive to the improvement of its economic and social benefits.

There is a need for coordination of interests between the protection and inheritance of agricultural cultural heritage tourism. The Measures for the Protection of Important Agricultural Cultural Heritage stipulates the institutions and the scope of protection for important agricultural cultural heritage protection. The overall lack of clear protection measures, especially the lack of protection funds and departmental responsibilities, makes it difficult to balance the appeals of stakeholders and affect the achievement of agricultural cultural heritage.

There are many types of agricultural cultural heritage, and the main responsibility for the protection of agricultural cultural heritage is the agricultural administrative department. The Ministry of Agriculture stipulated that during the investigation, it was found that it was difficult for the agricultural administrative department to coordinate with other departments, which led to the restriction of agricultural cultural heritage protection to the narrow sense of agriculture and the lack of effective protection of other types of agricultural cultural heritage. Insufficient investment in sustainable conservation funds makes it difficult to form a systematic long-term capital investment mechanism.

There are many types of agricultural cultural heritage; protection and inheritance involve huge interest groups. During the investigation, the relevant departments for the protection and transmission of agricultural cultural heritage all expressed the hope that the government would undertake the obligation of protection, increase investment, enhance the enthusiasm for protection, and give full play to the leading role of the government. As far as the government is concerned, the cultural heritage of the agricultural industry is a legacy of inheritance. Faced with the investment of funds from different stakeholders, it has exerted pressure on financial resources and management 
capabilities.

\section{The way to realize the value of agricultural cultural heritage}

\subsection{Pay full attention to the value of agricultural cultural heritage}

Tunisia signed a national charter on the protection of agricultural cultural heritage, protected important agricultural cultural heritage from destruction, and laid a solid foundation for the deep use of agricultural cultural heritage. Morocco has incorporated the plan for the protection and utilization of agricultural cultural heritage into its national development strategy to increase national cultural and agricultural industrial competitiveness.

\subsection{Establish full-time protection and utilization agencies}

Japan has established specialized agencies for the promotion of agricultural cultural heritage under the administration of agriculture in each of its heritage sites to protect traditional production methods of agricultural cultural heritage and formulate development plans. The Chilean government set up a special steering committee to guide the protection and development of the national agricultural cultural heritage.

\subsection{Form sustainable development of agricultural cultural heritage through the allocation of interests}

Algeria strives to find effective ways to encourage young people to return to their homeland and actively engage in agricultural activities to maintain the stability of the local heritage system. By giving full play to the role of the government, community, enterprises, and consumers, and forming a benefit community for the protection and utilization of agricultural cultural heritage, we are committed to finding a reasonable use of development methods and incentivizing sustainable protection of agricultural cultural heritage.

\subsection{Multi-channels to realize the economic value of agricultural cultural heritage}

The government of the Chilean agricultural cultural heritage site negotiated with hotels and tourism authorities to jointly set up new tourist routes, established rural travel agencies, and vigorously promoted local tourism products, tourism services and cultural undertakings, making culture the driving force for local development. Through a series of effective conservation and development measures, Yunnan has made Hani Terraces a well-known cultural scenic spot at home and abroad, creating remarkable social and economic benefits for Yunnan Province.

\section{The path to realize the value of agricultural cultural heritage}

\subsection{Strengthen government-led designs and planning}

As a part of public resources, agricultural cultural heritage should be used as the dominant force for the top-level design and planning of agricultural cultural heritage development. In terms of the protection of agricultural cultural heritage, it has clarified the management agencies and established a unified management and coordination organization that includes departments such as agriculture, forestry, marine fishery, water conservancy, culture, and tourism to participate in actions to improve management efficiency.

In terms of capital investment, a special fund for the use of agricultural cultural heritage has been established to clarify the responsibilities of the government and the market, and a model for the fine protection and industrialization of agricultural cultural heritage has been formed through modern financial instruments, attracting companies to investment and development with excellent products, and forming a sound market development model.

\subsection{Reasonable value assessment of agricultural cultural heritage development}

The activation of agricultural cultural heritage is an inevitable requirement for realizing the 
upgrading of the traditional industrial development model and optimizing the industrial structure, and has great practical significance for promoting economic and social development. The assessment of the value of agricultural cultural heritage is the key to the industrialization of agricultural cultural heritage. In the evaluation of value, according to the need of highlighting the unique features of agricultural cultural heritage, it strengthens the consciousness of characteristic evaluation. Based on the assessment of the regional cultural resources industry value, the uniqueness of resource value is emphasized, and it can be matched and integrated with specific industries to achieve comprehensive performance in terms of benefits and effects.

\subsection{Clustering and industrialization of agricultural cultural heritage}

Get rid of the current agricultural cultural heritage is too dependent on tourism and sightseeing mode, carry out multi-channel, diversification, three-dimensional development, in the true sense to achieve resource activation, industrial activation, social activation. The industrialization of agricultural cultural heritage can reduce the pressure of resource reserves brought about by traditional industries, transform traditional industries by culture, activate traditional economic vitality, and promote the re-development of traditional economy. Under the background of downward pressure on domestic and foreign economies, traditional industries urgently need to transform their own production capacity advantages into market advantages, explore the path of economic growth, and achieve all-round market opening, resource integration, and economic sharing.

\subsection{Design modularization and reproduce development plans to improve development efficiency}

The module of agricultural cultural heritage development should show the essence of agricultural cultural heritage and highlight the value of agricultural cultural heritage. Based on the regional agricultural cultural heritage and other industrial resources, in conjunction with the overall plan for regional economic development, we will focus on displaying agricultural cultural heritage in specific regions and create a full range of features including planting, breeding, processing, popular science, experience, and tourism. Copy the development path and build related industrial clusters.

\subsection{Incorporate agricultural cultural heritage into Fujian's cultural brand building strategy}

Actively combine the activation of agricultural cultural heritage with the strategies of beautiful rural construction, leisure agriculture, rural tourism development, precision poverty alleviation, and the rise of Fujian cultural brand, enrich the development connotation of "fresh Fujian", and promote the cultural construction and soft power of the core area of the Silk Road in the sea The promotion will eventually promote the integration of the secondary and tertiary industries and enhance the overall cultural competitiveness of the province.

\section{Conclusion}

The activation of agricultural cultural heritage is a new reflection on the protection and development path of agricultural cultural heritage in the context of increasing cultural needs and increasing awareness of cultural protection and heritage. The integration of agricultural cultural heritage with the strategy of activating beautiful China and rural revitalization and promoting the integration of 12 industries will become an important part of the cultural confidence of the new era.

\section{Acknowledgement}

This study was supported by 2016 Philosophical and Social Science Research Project of Fujian Province "The Impact of Village Governance Structure on the Effective Supply of Rural Tourism Goods" (No. FJ2016B099); 2016 Fujian Young and Middle-aged Teacher Education Research Project "Village Gov-ernance Structure on the Impact of Rural Tourism Performance" (No. JAS160156). 


\section{References}

[1] He L, Min Q W. The role of Multi-functionality of Agriculture in sustainable tourism development in Globally Important Agricultural Heritage Systems (GIAHS) sites in China. [J]. Journal of Resources and Ecology, 2013, 4(3):250-257.

[2] Yoon W K, Choi S I. Establishment of the Agriculture and Fisheries Heritage System in Korea[J]. Journal of Agricultural Extension \& Community Development, 2012, 19(2).

[3] Zhang Y X, Liu M C, Min Q W, et al. Calculation of Price Compensation of Agriculture Products in the Period of Organic Conversion in Agricultural Heritage Sites-Taking Paddy Rice of Hani Terrace in Honghe County of Yunnan Province as an Example[J]. Journal of Natural Resources, 2015, 30(3):374-383.

[4] Li W H, Liu M C, Min Q W. Agricultural heritage conservation: new opportunity for developing eco-agriculture. [J]. CHINESE JOURNAL OF ECO-AGRICULTURE, 2012, 20(6):663-667.

[5] Daugstad K, Ronningen K, Skar B. Agriculture as an upholder of cultural heritage? Conceptualizations and value judgments: A Norwegian perspective in international context[J]. Journal of Rural Studies, 2006, 22(1):67-81.

[6] Nahuelhual L, Carmona A, Laterra P, et al. A mapping approach to assess intangible cultural ecosystem services: The case of agriculture heritage in Southern Chile[J]. Ecological Indicators, 2014, 40(5):90-101.

[7] Wang Degang. Cultural self-confidence, balance of interests is the basis for establishing the ethical relationship of rural tourism [J], Tourism Journal, 2014.11.

[8] Linsheng Lin, Xiangxiang Ma. The problems and countermeasures faced by the integrated development of tourism and urban construction [J], Journal of Tourism, 2016.01.

[9] Zhu Xiaohui, Fu Jihong. Innovative research on reform of tourism management system under modern governance system [J], Management World, 2015.03. 